Available online at GSC Online Press Directory

GSC Biological and Pharmaceutical Sciences

e-ISSN: 2581-3250, CODEN (USA): GBPSC2

Journal homepage: https://www.gsconlinepress.com/journals/gscbps

(RESEARCH ARTICLE)

\title{
Intestinal helminthiasis and human/environmental factors among primary school pupils in Okuzu-Oba, Anambra State, Nigeria
}

\author{
Udechukwu Chukwunonso Uche ${ }^{1,}{ }^{*}$ and Ekejindu Ifeoma Mercy ${ }^{2}$ \\ ${ }^{1}$ Department of Biological Sciences, Abubakar Tafawa Balewa University, PMB 0248, Bauchi, Nigeria. \\ 2 Department of Microbiology and Parasitology, College of Health Sciences, Nnamdi Azikiwe University, Nnewi, Nigeria.
}

Publication history: Received on 06 May 2019; revised on 20 May 2019; accepted on 24 May 2019

Article DOI: https://doi.org/10.30574/gscbps.2019.7.2.0084

\begin{abstract}
Intestinal helminthiasis, a health problem in the developing world; is due to factors that promote their survival and transmission, with children at the highest risk. Using direct wet preparation and Formol-Ether concentration techniques; survey carried out revealed an overall prevalence rate of 34.8\%. These parasites were identified with their corresponding rates: hookworms - 26.8\%, Ascaris lumbricoides - 9.4\%, Strongyloides stecoralis - 1.7\%, Trichuris trichura $-1.7 \%$, Enterobius vermicularis - 0.7\% and Giardia lamblia - 0.7\%. A sample size of 138 pupils including 74 male and 64 females, of whom $35.1 \%$ and $34.8 \%$ were infected respectively. Four age groups: $4-6,7-9,10-13$ and 14 - 16 had infection rates of: 33.3\%, 26.7\%, 42\% and 25\% respectively, with significant difference among the age groups $(\mathrm{P}>0.05)$. Sources of drinking water included bore-hole and stream/river, with infection rates according to the sources as: $41.3 \%$ and $21.7 \%$ respectively, difference highly significant $(\mathrm{P}>0.01)$. Drinking water purification by boiling was analyzed and $16.7 \%$ of those who did were infected while $35.6 \%$ of those who did not purify were infected, difference highly significant $(\mathrm{P}>0.01)$. Infection rates according to toilet facility type at home were: $50 \%$ for no toilet, $41.2 \%$ for water closet and $33.6 \%$ for pit toilet owners. Toilet facility at home notwithstanding, some prefer to defecate in the bush of whom $56.7 \%$ were infected, while $30.8 \%$ of those who use toilet facility at home were infected, difference highly significant $(\mathrm{P}>0.01)$. This research showed high prevalence rate, poor sanitary conditions and lack of good water supply. Health education, Mass chemotherapy and provision of good water are recommended.
\end{abstract}

Keywords: Intestinal helminthiasis; Human/environmental factors; Primary school pupils; Okuzu-Oba; Anambra State; Nigeria

\section{Introduction}

Infection by intestinal parasites has classically been considered a health problem in rural communities in the developing world [1]. This takes highest toll in Middle East and African countries as noted by Karrar\& Rahim [2]. It was observed that among the intestinal parasites, helminthes are the most important parasites possessing pathogenicity for man, especially children among the poor, with low sanitary level of life [3]. Among the intestinal parasites of man, nematodes are more rampant in the tropics and sub-tropics [4]. Epidemiological studies have demonstrated an alarmingly high frequency of ill health in apparently healthy Nigerian school children [5]. A school child must be physically, mentally, and emotionally healthy in order to derive enough benefits from any educational programme. In the poor urban and rural habitations, human and environmental factors promote the survival and transmission of intestinal helminthic infections, and aggravate the impact on the people, with children at the highest risk. Unsanitary disposal of faeces, little or no good water supply and poor personal hygiene pose great health hazards in most semi-urban and urban communities today [6]. In an analysis of about 144 studies in agreement with the objectives of the International Drinking Water Supply and Sanitation Decade (IDWSSD), a review of the health impact of water and sanitation interventions

\footnotetext{
* Corresponding author

E-mail address: ubcuche@gmail.com
} 
were made on some intestinal parasitic infections [7]; this is to illustrate the variety of mechanisms through which improved water and sanitation can promote health. Four basic aspects were considered: sanitation (i.e human excreta disposal), water quality, personal hygiene and domestic hygiene. Result showed that the incidences and prevalence or severity of diseases are reduced by water and sanitary interventions. In a parasitological survey at Sagbama community of Niger Delta, Nigeria, it was demonstrated that types of toilet facility and source of drinking water among other factors were important determinants of the level of parasitic infection in a rural setting [8]. Infection rates in relation to toilet facility type showed that use of "bush" as convenience recorded the highest rate of parasitic infection (42\%). Others are pit (27.7\%), bucket (20.9\%) and water closet (15.5\%) [8]; the rate of infection in relation to drinking water source was also noted thus: river/stream (35.9\%), well/pond (32.8\%) and pipe-borne (12.5\%). As before discussed, the intestinal helminthic infections are food, water and soil-borne, hence transmission is by faeco-oral contaminative pathway or soilskin contact for hookworms and Strongyloides infections.

\section{Material and methods}

\subsection{Study design}

This was a field study to investigate infection with intestinal helminthes in relation to human/environmental factors among primary school children in Okuzu village of Oba in Anambra state Nigeria.

\subsection{Sample collection and examination}

Stool samples were collected from $3^{\text {rd }}$ June to $10^{\text {th }}$ July, 2003 from a total of 138 pupils from two primary schools in Okuzu: United and Umuezegbogu Primary schools. The populations of the schools were 158 for the former and 105 for the later. 73 and 65 pupils respectively were randomly selected for the research.

Stool samples were analysed by the direct macroscopic examination and microscopy (direct wet preparation and formol-ether concentration technique) as outlined by Cheesbrough [4].

\subsection{Human/environmental factors}

With the aid of well-structured questionnaire, information were obtained from the pupils on sex, age, toilet facility and usage, source of drinking water, drinking water purification by boiling and attitude to foot wears.

\subsection{Data analysis procedure}

Infection rates in relation to human/environmental factors were analysed using the Chi-Square statistical analysis.

\section{Results}

Table 1 Summary of infection rate among age groups an between sexes

\begin{tabular}{llll}
\hline Criteria & Total tested & No. infected & Infection rate \\
\hline Total & 128 & 48 & $34.8 \%$ \\
Male & 74 & 26 & $35.1 \%$ \\
Female & 64 & 22 & $34.4 \%$ \\
$4-6$ yrs & 12 & 4 & $33.3 \%$ \\
$7-9$ yrs & 45 & 12 & $26.7 \%$ \\
$10-13$ yrs & 69 & 29 & $42.0 \%$ \\
$14-16$ yrs & 12 & 3 & $25.0 \%$ \\
\hline
\end{tabular}

Out of a total of 138 pupils, 48 (34.8\%) were infected with at least one intestinal parasite. Infection rates of the sexes were $35.1 \%$ (males) and $34.4 \%$ (females), showing no significant difference ( $\mathrm{P}>0.05)$. The infection rates among four age groups are: $33.3 \%(4-6$ yrs), $26.7 \%(7-9$ yrs), $42.0 \%(10-13 \mathrm{yrs})$ and $25 \%(14-16 \mathrm{yrs})$. The difference in the infection rate was statistically significant at $\mathrm{P}>0.05$ 
Table 2 Prevalence rates of different parasites encountered

\begin{tabular}{lll}
\hline Parasite name & No. of pupils infected & Prevalence rate (\%) \\
\hline Hookworms & 37 & 26.8 \\
Ascarislumbricoides & 13 & 9.4 \\
Strongyloides & 2 & 1.4 \\
Trichuristrichura & 2 & 1.4 \\
E. vermicularis & 1 & 0.7 \\
G. lamblia & 1 & 0.7 \\
Multiple infection & 7 & 5.1
\end{tabular}

From table 2 above, hookworms show the highest prevalence rate of $26.8 \%$. It is also worth noting that multiple infection rate is $5.1 \%$.

Table 3 Infection rates according to drinking water source

\begin{tabular}{lll}
\hline Water source & No. of pupils & No. (\%) infected \\
\hline Bore hole & 92 & $38(41.3)$ \\
Stream/river & 46 & $10(21.7)$
\end{tabular}

The community did not have pipe-borne water supply and so sourced water from either bore-hole or stream. The difference in the prevalence rates of the different water sources was highly significant $(P>0.001)$.

Table 4 Prevalence rates in relation to boiling of drinking water

\begin{tabular}{lll}
\hline Boiling & No. of pupils & No. (\%) infected \\
\hline Yes & 6 & $1(16.7)$ \\
No & 132 & $47(35.6)$ \\
\hline
\end{tabular}

Out of 138 pupils, 6 professed to purify water at home for drinking by boiling, of whom $16.7 \%$ were infected; while 132 professed not to boil, of whom 35.6 were infected. Statistically, the difference between attitudes to water purification by boiling is highly significant (P>0.01).

Table 5 Prevalence rate in relation to type of toilet facility at home

\begin{tabular}{lll}
\hline Toilet facility & No. of pupils & No. (\%) infected \\
\hline Water closet & 17 & $7(41.2)$ \\
Pit & 119 & $40(33.6)$ \\
None & 2 & $1(50)$ \\
\hline
\end{tabular}

Although the infection rate was highest among those that had no toilet facility at home, the other groups also show high infection rate. There is no statistically significant difference in the infection rates.

Table 6 Infection rate in relation to usage of toilet facility at home and preference of defecation in the bush

\begin{tabular}{lll}
\hline Usage & No. of pupils & No. (\%) infected \\
\hline Home & 78 & $24(30.8)$ \\
Bush & 60 & $34(56.7)$ \\
\hline
\end{tabular}

78 pupils professed to constantly use the toilet facility at home of whom $30.8 \%$ were infected, while 60 were used to defecating in the bush of whom $56.7 \%$ were infected. Statistical analysis showed that the difference is highly significant $(P>0.01)$. 
Table 7 Prevalence rate according to putting on foot wears

\begin{tabular}{lll}
\hline Attitude & No. of pupils & No. (\%) infected \\
\hline Positive & 29 & $8(27.6)$ \\
Negative & 107 & $40(37.4)$ \\
\hline
\end{tabular}

There was no statistically significant difference between the two attitude groups, but the high number of pupils that moved about bare-footed is quite alarming.

\section{Discussion}

Intestinal parasitic infections remain an important cause of morbidity and sometimes mortality in developing countries, particularly among children [2]. A growing body of evidence obtained through epidemiological surveys suggest that intestinal helminth infections are associated with household environment and sanitation $[3,7,9]$

This study revealed an overall prevalence rate of 34.8\%, which is comparable to the research finding of Akabogu [10], on intestinal helminthes among pre-school children in the Niger Delta. The helminth species encountered showed infection rate of hookworms to be highest $-26.8 \%$. Other parasites are: A. lumbricoides $-9.4 \%$, S. stecoralis $-1.7 \%, T$. trichiura $-1.7 \%$ and E. vermicularis - $0.7 \%$ (table 2). In Egypt, researchers noted infection rates of A. lumbricoides$46.5 \%$, T. trichura- $17 \%$ and hookworms- $0.2 \%$ [9]. The differences in the prevalence rates could be due to variation in climatic and human/environmental factors. The high rate of hookworm infection rate in this research can be linked with the high number of the pupils who walks about barefooted (see table 7), because hookworm infection establishes on infective larva contact with the skin [11]. All age groups show susceptibility to helminthiasis with $10-13$ years with the highest infection rate of $42 \%$ (table 1). This could be explained with the supposition that this age group seem to be the most active in playfulness (outdoors) and care-freeness. The rates are high enough and comparable to other research finding, which showed age 6 - 15years as having highest infection rate, with adults $>45 y e a r s$ showing least infection rate [8]. The impact of source of drinking water and water purification by boiling on the infection rates were analyzed (see tables $3 \& 4$ ). The infection rates are high for both sources, but higher among those sourcing from borehole. The difference is highly significant $(\mathrm{P}>0.05)$. The high rate of infection among those sourcing from bore-hole may have resulted from in between transit contamination. Purification of drinking water by boiling proved to be a good tool against infection as those who did were less infected (table 4), and the difference between the two groups is highly significant $(\mathrm{P}>0.01)$. The high prevalence rates of both water sources is a good indication of need of potable water supply and enhancement of hygiene among the pupils. Infection rates among different toilet facilities at home showed that those with no toilet facility at home are most infected (50\%), followed by water closet users :- $41.2 \%$ and lastly pit toilet users :- $33.6 \%$; the differences are statistically insignificant, but the rates are alarmingly high, this is comparable to other research findings works [5,7]

Majority of the pupils, about 77.5\%, were in the habit of defecating in the bush instead of in the home toilet (see table 6), this is a major contributor to the high infection rate among them. The difference in the infection rate between those who prefer bush and those who use home for toileting is highly significant $(\mathrm{P}>0.01)$.

\section{Conclusion}

Intestinal helminthiasis prevalence rate is very high among the primary school children in Okuzu community. This could be due to lack of good water supply, inadequate human waste disposal, poor hygiene and low health education level in the community. The following are therefore recommended: Health education and healthy practices awareness is needed in the community - in schools, churches and community forum, provision of pottable water, mass chemotherapy with anthelminthics.

\section{Compliance with ethical standards}

\section{Acknowledgments}

The authors thank the Managements, staff and pupils of United and Umuezegbogu Primary Schools, Okuzu Oba, AnambraState for the cooperation given us during this research work. The support of the Laboratory Technologists of the NnamdiAzikiwe University Teaching Hospital, Nnewi is also appreciated. 


\section{Disclosure of conflict of interest}

The authors declare no conflict of interest of any form.

\section{Statement of informed consent}

Informed consent was obtained from all individual participants included in the study.

\section{References}

[1] WHO. (1987). Public health significance of intestinal parasitic infections. Bulletin of WHO, 65, 575 - 588.

[2] Karrah ZA and Rahim FA. (1995). Prevalence and risk of parasitic infections among under five Sudanese children. A community based study. East African Medical Journal, 72(2), 103 - 109.

[3] Ezigbo JC. (1983): Helminthiasis in the tropics: problems and prospects. Nigerian Journal of Parasitology, 4(1), 13-19.

[4] Cheesbrough M. (1999). District Laboratory Practice in Tropical Countries Part 1. Cambridge University Press. ISBN: 0521665485, 454.

[5] Salako AA. (2001). Effects of portable water availability in intestinal parasitism among rural school children with sewage disposal in Lagos State. Nigerian Medical Practitioner 39(3/4), 30 - 34.

[6] Martin J and Cross I. (1984). Intestinal parasitic infections of children in the Sahel, Upper-Volta. West African Journal of Medicine, 3(4), $341-344$.

[7] Esry SA, Potash JB, Roberts L and Shiff C. (1991). Effects of improved water supply and sanitation on ascariasis, diarrhea, dracunculiasis, hookworm infection, schistosomiasis and trachoma. Bulletin of WHO, 69(5), 609 - 621.

[8] Agi PI. (1995). Pattern of infection of intestinal parasites in Sagbama community of Niger Delta, Nigeria. West African Journal of Medicine, 14(1), 39 - 42.

[9] Mahfouz AAR, Morshedy HE, Farghaly A and Khalil A. (1997): Ecological determinants of intestinal parasitic infection among pre-school children in urban squatter settlement of Egypt. Journal of Tropical Paediatrics, 43, $341-344$.

[10] Akabogu OA. (1984). Intestinal parasitic infections in pre-school children in the Niger Delta. Journal of Hygiene, Epidemiology, Microbiology and Immunology, 30, 99 - 102.

[11] Markell EK, John DT and Krotoski WA. (1999). Medical Parasitology, Eighth Edition. W.B. Saunders Company. Philadelphia.

\section{How to cite this article}

Udechukwu CU and Ekejindu IM. (2019). Intestinal helminthiasis and human/environmental factors among primary school pupils in Okuzu-Oba, Anambra State, Nigeria. GSC Biological and Pharmaceutical Sciences, 7(2), 141-145. 